\title{
Effects of lightning and other meteorological factors on fire activity in the North American boreal forest: implications for fire weather forecasting
}

\author{
D. Peterson ${ }^{1}$, J. Wang ${ }^{1,2}$, C. Ichoku ${ }^{2}$, and L. A. Remer ${ }^{2}$ \\ ${ }^{1}$ Department of Earth and Atmospheric Sciences, University of Nebraska, Lincoln, NE, USA \\ ${ }^{2}$ Laboratory for Atmospheres, NASA Goddard Space Flight Center, Greenbelt, MD, USA
}

Received: 22 February 2010 - Published in Atmos. Chem. Phys. Discuss.: 31 March 2010

Revised: 21 June 2010 - Accepted: 11 July 2010 - Published: 23 July 2010

\begin{abstract}
The effects of lightning and other meteorological factors on wildfire activity in the North American boreal forest are statistically analyzed during the fire seasons of 2000-2006 through an integration of the following data sets: the MODerate Resolution Imaging Spectroradiometer (MODIS) level 2 fire products, the 3-hourly 32-km gridded meteorological data from North American Regional Reanalysis (NARR), and the lightning data collected by the Canadian Lightning Detection Network (CLDN) and the Alaska Lightning Detection Network (ALDN). Positive anomalies of the $500 \mathrm{hPa}$ geopotential height field, convective available potential energy (CAPE), number of cloud-to-ground lightning strikes, and the number of consecutive dry days are found to be statistically important to the seasonal variation of MODIS fire counts in a large portion of Canada and the entirety of Alaska. Analysis of fire occurrence patterns in the eastern and western boreal forest regions shows that dry (in the absence of precipitation) lightning strikes account for only $20 \%$ of the total lightning strikes, but are associated with (and likely cause) $40 \%$ of the MODIS observed fire counts in these regions. The chance for ignition increases when a threshold of at least 10 dry strikes per NARR grid box and at least 10 consecutive dry days is reached. Due to the orientation of the large-scale pattern, complex differences in fire and lightning occurrence and variability were also found between the eastern and western sub-regions. Locations with a high percentage of dry strikes commonly experience an increased number of fire counts, but the mean number of fire counts per dry strike is more than $50 \%$ higher in western boreal forest sub-region, suggesting a geographic and possible
\end{abstract}

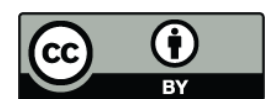

Correspondence to: J. Wang (jwang7@unl.edu) topographic influence. While wet lightning events are found to occur with a large range of CAPE values, a high probability for dry lightning occurs only when $500 \mathrm{hPa}$ geopotential heights are above $\sim 5700 \mathrm{~m}$ and CAPE values are near the maximum observed level, underscoring the importance of low-level instability to boreal fire weather forecasts.

\section{Introduction}

The boreal forest of North America, which is dominated by dense evergreen vegetation, covers an east-west oriented belt of land south of the tundra regions, and is a favorite spawning ground for wildfire activity each summer (Ichoku et al., 2008a). With plenty of available fuel to burn, wildfires often reach 200 hectares in size and are commonly left to burn unimpeded because of their remoteness (Stocks et al., 2002). In Alaska alone, roughly 400,000 hectares burned annually during the period 1990 to 1996 (Boles and Verbyla, 2000). In the large boreal forest in Canada, 2.75 million hectares was found to burn annually during the 1990s (Stocks et al., 2002). In addition to the ecological health hazard and change in surface albedo caused by biomass burning, enormous amounts of particulate matter, as well as carbon monoxide, carbon dioxide, methane, and other trace gases are emitted into the atmosphere, creating concerns for air quality and other atmospheric impacts (e.g. Spracklen et al., 2007; Jordan et al., 2008). The need for an accurate assessment of direct and indirect fire impacts including the development of effective mitigation strategies underscores the importance of studying the potential causes of wildfire ignition in the boreal region.

Attempts have been made during the past several decades to discern the role of local meteorology, topography, climate,

Published by Copernicus Publications on behalf of the European Geosciences Union. 
and land use in the formation of intense boreal fire seasons (e.g. Skinner et al., 1999; Stocks et al., 2002). Flannigan and Harrington (1988) described the enhanced effect of prolonged dry and warm periods on fire intensity and duration. Skinner et al. $(1999,2002)$ showed that regions under the influence of positive $500 \mathrm{hPa}$ geopotential height anomalies in Canada commonly experience above average fire seasons. In addition, Fauria and Johnson (2006) found that positive height anomalies must persist for approximately 10 days to have a significant impact on fire activity. These earlier studies suggest that persistent positive height anomalies result in a warmer and drier atmosphere with enough convective activity present for the production of isolated lightning events that ignite fires. Quantitatively, Boles and Verbyla (2000) found that $93 \%$ of the land burned in Alaska during 1990-1996 was a result of lightning-started fires, and Stocks et al. (2002) found that $\sim 72 \%$ of the large fires in Canada during 19591997 were associated with lightning activity. These fires are sparked by thunderstorms producing "dry" lightning, which can occur by any of the following scenarios: (a) the thunderstorm is high-based and most of the precipitation evaporates before reaching the ground; (b) lightning strikes outside the rain shaft of a "wet" thunderstorm; (c) lightning occurs with a rapidly moving thunderstorm where rainfall does not have sufficient time to accumulate (Rorig and Ferguson, 1999, 2002).

Several fire weather indices have also been developed to guide forecasts for the potential of fire ignition and spread. The Haines Index, which is widely used in the United States, is an integer scale (1-6) that indicates the potential for fire ignition and growth based on two equally weighted ingredients for moisture and stability, respectively derived from the surface dew point depression and atmospheric lapse rate (Haines, 1988; Potter et al., 2008). Unstable conditions in the lower troposphere commonly result in a greater chance for lightning strikes, higher smoke plumes, stronger entrainment of the air near the fires, and faster spread rate, all of which can lead to "extreme fire behavior" (Werth and Ochoa, 1993).

In contrast to the Haines Index, the fire indices used in the Canadian boreal forest regions generally disregard atmospheric instability variables and put more focus on biomass moisture content. For example, the Canadian Fire Weather Index (FWI) is based on the use of surface temperature, relative humidity, rainfall, and wind speed to derive the amount of biomass moisture content used for assessing fire potential and spreading in the unique boreal ecosystem (Amiro et al., 2004). The same index is also used in Alaska to complement their own Alaska Fire Potential Index (FPI), which is an integer scale from 1 to 100 ranking the level of biomass moisture content for specific vegetation types based on the satellite derived Normalized Difference Vegetation Index (NDVI) along with other surface observations (Burgan et al., 1998).

While the key meteorological factors for fire ignition and spread are qualitatively known, their interplay, which results in lightning activity that ultimately ignites the fires, has not been quantitatively analyzed. This analysis is paramount to explaining the regional and interannual variability of wildfires in boreal North America. Even with instability recognized as a fundamental component of the Haines Index, there has never been an attempt to quantitatively assess the importance of this variable in fire ignition, especially over large temporal and spatial scales in the boreal forest. Furthermore, instability is paramount in determining the potential for convection and dry lightning (Rorig and Ferguson, 1999, 2002); but little work has been done to investigate its relationship with dry lightning strikes and fire locations across boreal North America.

The lack of a study on possible relationships between lowlevel instability and other meteorology factors in the formation of lightning and fire ignition is partially due to the dearth of spatiotemporally collocated meteorological, lightning, and fire data. Often, scattered reports of weather, fire, and burned area from ground observations are used to characterize fire variability. Admittedly, these reports are not very reliable in describing the fire spatial distribution, temporal distribution (including the start and end dates), and intensity over the vast, sparsely populated boreal forests (Stocks et al., 2002; Flannigan and Wotton, 1991).

This study builds upon the following observational advancements to systematically investigate the cause of the variability in wildfire activity throughout boreal North America: (a) the development of ground-based lightning observation network with large spatial coverage in Alaska and Canada; (b) the high spatiotemporal meteorological reanalysis over North America; and (c) the near daily measurements of fire location and intensity with global coverage from NASA's MODerate Resolution Imaging Spectroradiometer (MODIS). In addition to discerning fire locations with unprecedented accuracy (e.g. Justice et al., 2002), MODIS can measure fire radiative power (FRP), a parameter directly reflecting fire intensity and emission. This product, pioneered by MODIS, resulted in the first quantitative global survey of fire intensity (Ichoku et al., 2008a). By integrating the data sources $(\mathrm{a}-\mathrm{c})$ at relatively high spatiotemporal resolution in this paper, a detailed statistical analysis is conducted to understand the meteorological conditions necessary for dry and wet lightning events. The analysis further quantifies the effect of lightning on boreal fire activity characterized by MODIS for the fire seasons of 2000-2006. Section 2 of this paper describes the regions of study. Section 3 describes each data source in detail and the data integration algorithm. Sections 4 and 5 respectively present the spatiotemporal statistical analysis for a large-scale and focused sub-regional analysis. Section 6 addresses the specific causes of dry lighting and their effects on fire ignition using a grid-based joint probability analysis. Section 7 concludes the paper. 
Table 1. Specifics of the study regions displayed as red or black boxes in Fig. 1.

\begin{tabular}{llllll}
\hline Region Name & Min Lon & Max Lon & Min Lat & Max Lat & Total NARR Grid Boxes \\
\hline A (Alaska) & -170 & -140 & 55 & 75 & 3222 \\
B (Canada) & -140 & -80 & 50 & 70 & 7287 \\
1 & -155 & -147 & 62.5 & 66.5 & 174 \\
2 & -146 & -138 & 62.5 & 66.5 & 175 \\
3 & -137 & -129 & 60 & 64 & 187 \\
4 & -118 & -110 & 58 & 62 & 198 \\
5 & -107 & -99 & 54.5 & 58.5 & 211 \\
6 & -98 & -90 & 52 & 56 & 221 \\
Western Domain & \multicolumn{5}{c}{ Regions 1-3 } \\
Eastern Domain & \multicolumn{5}{c}{ Regions 4-6 } \\
\hline
\end{tabular}

\section{Regions and time period of study}

As shown in Fig. 1, the North American boreal forest is divided into two large regions including the majority of Alaska (region A) and a portion of Canada west of the Great Lakes and Hudson Bay (region B). The boundaries of these two regions (defined in Table 1) follow that of Ichoku et al. (2008a) in which 36 regions, each containing a dominant ecosystem type (such as boreal forest in this study), are defined across the globe to study MODIS-observed wildfire patterns and intensity. Therefore, regions A and B are used as a preliminary analysis step.

While the large areas of regions A and B are suitable for studying the variability of fires in large temporal (monthly to yearly) and spatial (synoptic) scales, detailed analysis of meteorological factors affecting fire ignition requires the investigation of fire variability in the core of boreal forest at fine spatial and temporal scales. For this purpose, 6 smaller regions (defined in Table 1 and labeled from 1 through 6 in Fig. 1) are created to include only the core of the boreal forest belt with the caveat that it is nearly impossible for each region to contain exactly the same type of vegetation. Because regions 1-3 are located in the mountainous boreal forest of Alaska and Canada, they are grouped together as the western study domain in our analysis, whereas regions 4-6 in the relatively flat boreal forest in Canada are grouped to form an eastern study domain. Such grouping allows the analysis to focus on the effect of meteorological factors on fire ignition in each domain, while the likely effect of a positive relationship between lightning strikes and elevation, as shown in previous studies (e.g. Reap, 1991; Dissing and Verbyla, 2003), only influences the western domain. Furthermore, the eastern domain includes the portion of Canada known to have the highest frequency of fires, where up to $0.74 \%$ of the total land area burns annually (Stocks et al., 2002; Skinner et al., 2002), and the western domain covers nearly all of the boreal forest in Alaska known to have regular fire activity. It is also assumed that the anthropogenic influence on fire igni-

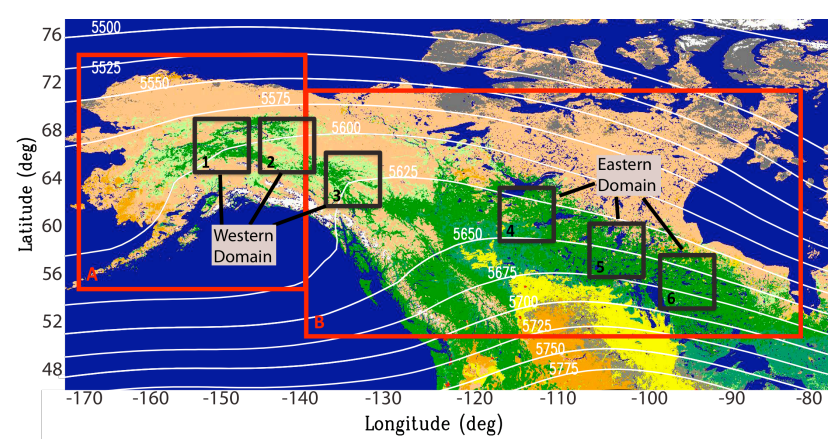

Fig. 1. Global MODIS derived ecosystem map. Red boxes delineate the large study regions for Alaska (A) and Canada (B). The black boxes delineate the small boreal forest regions (1-6) defined for focused analysis in this study and the combination of regions 1-3 (4-6) is referred as the western (eastern) domain in the main text. Dark green areas comprise the dense evergreen needle leaf forest common in boreal regions, the tan shaded area is open tundra shrub-land, yellow is croplands, and orange is grassland. The white contours indicate the mean $500 \mathrm{hPa}$ geopotential height field for the fire season (June-August) for 2000-2006.

tion in the western and eastern domains is low in comparison to other forested regions across North America (Stocks et al., 2002; Boles and Verbyla, 2000).

The fire season (when the vast majority of fires occur) in the high latitudes is limited by the duration of a short warm season from June to August (Skinner et al., 1999; Stocks et al., 2002; Fauria and Johnson, 2006). Therefore, the fire variability in this three-month time period beginning in 2000 (when the MODIS fire data starts) and ending in 2006 (when this study began) is the focus of this investigation. Consequently, the data are collected and integrated accordingly to match the time period and regions of this study described above. 


\section{Data description and integration}

\subsection{MODIS fire products}

The MODIS sensor aboard the polar-orbiting Terra satellite (launched 19 December 1999) provides all of the fire data used in this study. Specifically, this study uses the MODIS level 2, collection 4 fire product with a spatial resolution of $1 \mathrm{~km}$ at nadir (Giglio et al., 2003; Ichoku et al., 2008a). Terra MODIS has a swath width of $2330 \mathrm{~km}$ with equator crossing times of 10:30 a.m. and 10:30 p.m. local time (Kaufman et al., 2003). Its swaths overlap poleward of $50^{\circ}$ latitude, resulting in complete daytime and nighttime spatial coverage every $24 \mathrm{~h}$ for the boreal forest including the general study region of North America $\left(50-75^{\circ} \mathrm{N}\right)$ used in this study (e.g. Ichoku et al., 2008a).

When compared to earlier satellite sensors, MODIS is unparalleled in fire detection because of its ability to differentiate a wide range of fire intensities, as a result of the synergy between its two $4 \mu \mathrm{m}$ (more precisely $3.96 \mu \mathrm{m}$ ) channels whose dynamic ranges are complementary. The first $4 \mu \mathrm{m}$ channel with a low signal-to-noise ratio saturates at $331 \mathrm{~K}$ brightness temperature, and thus serves as the primary channel for fire detection (Justice et al., 2002); the second channel saturates at $500 \mathrm{~K}$ and is used to detect fires with brightness temperatures higher than $331 \mathrm{~K}$ (Justice et al., 2002). Other satellites with fire detection capabilities, such as the Advanced Very High Resolution Radiometer (AVHRR) and the Along Track Scanning Radiometer (ASTR), have much lower saturation brightness temperatures of about $325 \mathrm{~K}$ and $312 \mathrm{~K}$ respectively (e.g. Gao et al., 2007; Kelha et al., 2003), and are not capable of distinguishing between weak and intense fires.

The MODIS fire detection algorithms retrieve fire locations through a hybrid, contextual process culminating in the absolute detection of a fire pixel. A set of thresholds for reflectance at $0.86 \mu \mathrm{m}$ and brightness temperature $(\mathrm{T})$ at the $4 \mu \mathrm{m}$ and $11 \mu \mathrm{m}$ infrared channels (hereafter $T_{4}$ and $T_{11}$ ) are used to remove sun glint, cloudy pixels, and to identify potential fire pixel (Justice et al., 2002; Giglio et al., 2003). Potential fire pixels are defined as those with $T_{4}>325 \mathrm{~K}$ ( $>310 \mathrm{~K}$ ) and $T_{4}-T_{11}>20 \mathrm{~K}(>10 \mathrm{~K})$ for daytime (night) observations (Giglio et al., 2003). The second step is relative fire detection, which relates the brightness temperature of the potential fire pixel with the surrounding background pixels and applies to all cloud-free and sun glint-free pixels regardless of their classification in the first step. A neighborhood search is conducted within a square window that progressively widens as necessary around a potential fire pixel until at least $25 \%$ of the pixels in the square are valid background pixels (absence of fire) and the number of these valid pixels is at least eight. If enough valid background pixels are found, the mean and absolute deviation of their $T_{4}, T_{11}$, and $T_{4}-T_{11}$ are computed (Giglio et al., 2003). Finally, the absolute check in the first step and relative detection in the second step are combined (as a Boolean union) to classify a potential pixel as a real fire pixel.

In addition to discerning fire location and brightness temperature, the MODIS fire algorithm also retrieves the fire radiative power (FRP) using only the $4 \mu \mathrm{m}$ channels: (Kaufman et al., 1998a, b): $F R P=4.34 \times 10^{-19}\left(T_{4}^{8}-T_{4 b}^{8}\right)$ where $T_{4 b}$ is the background temperature, yielding FRP in units of MW per pixel area (Kaufman et al., 1998a). It has been shown that the FRP can be used as a quantitative indicator for fire intensity and is proportional to both the fire's fuel consumption and smoke emission rates (e.g. Wooster et al., 2002, 2003, 2005; Ichoku and Kaufman 2005; Roberts et al., 2005, 2008; Ichoku et al., 2008a, b; Jordan et al., 2008). In contrast to earlier sensors, MODIS is currently the only operational satellite sensor designed to specifically measure FRP globally (e.g. Kaufman et al., 1998a, b; Ichoku et al., 2008a). The higher saturation temperatures of MODIS allow for the derivation of FRP for nearly every fire it detects, because fire pixels with $T_{4} \gg 500 \mathrm{~K}$ seldom occur (Ichoku et al., 2008a).

The major caveats of the MODIS fire products in the boreal regions are sun glint, coastal false alarms (water reflectance), and clouds that may hamper the fire detection. These non-idealities are accounted for by applying water masks and cloud masks in the fire detection algorithm (Kaufman et al., 1998a; Giglio et al., 2003). Validation studies showed that the probability of fire detection by the collection 4 algorithm in the boreal forest is $\sim 80-100 \%$ during the day and near $100 \%$ at night (Giglio et al., 2003). The smallest detectable fire size in any given pixel was found to be $\sim 100 \mathrm{~m}^{2}$ (Giglio et al., 2003). Though hard to validate directly and globally, MODIS FRP was found to be in good agreement with in situ measurements in several case studies (Wooster et al., 2003; Roberts et al., 2005; Ichoku et al., 2008a).

\subsection{Meteorological data}

Meteorological data are obtained from the North American Regional Reanalysis (NARR) database archived at the National Climatic Data Center (NCDC). Through data assimilation, the NARR blends a variety of observational data into the Eta model output containing 45 vertical layers over a mesh across the North American continent of $\sim 32 \mathrm{~km}$ grid spacing, providing a more detailed reanalysis of meteorological and surface variables (Ebisuzaki, 2004; Mesinger, 2006). The specific number of NARR grid boxes per study region ranges from 500-600 in the eastern and western domains to over 3000 in regions A and B (Table 1). A collection of NARR monthly means and 3-hourly data for several meteorological variables including soil and atmospheric moisture, instability, precipitation, etc. are used for analysis (Table 2). The surface-based convective available potential energy (CAPE) is used to address the role of low-level instability. Commonly included in convective forecasts, CAPE is directly related to the maximum potential vertical speed 
within an updraft; therefore, higher values indicate a greater potential for convection (thunderstorms).

\subsection{Lightning data}

Lightning data were obtained from the Canadian Lightning Detection Network (CLDN) owned by Environment Canada and the US Bureau of Land Management's Alaska Lightning Detection Network (ALDN). For the purposes of this paper, only cloud-to-ground (CG) discharges were considered. CG lightning commonly consists of several separate strokes (multiplicity) forming the individual flash. However, in this study, each large lightning flash was considered as a single strike regardless of the multiplicity. The lightning location and timing are measured from sensors using the timeof-arrival method or a combination of time-of-arrival and direction finding (Cummins et al., 1998; Burrows et al., 2002). Specifically, the CLDN uses 82 sensors across the country and roughly 34 of these are located in region B (Burrows et al., 2002). The ALDN uses 9 sensors concentrated in the center of the state (region A) where the majority of lightning events are known to occur (Dissing and Verbyla, 2003). The combination of sensors from the CLDN and ALDN provides spatial coverage for all relevant regions used in this study. Furthermore, the detection efficiency of CG lightning in the CLDN (ALDN) is roughly 85-90\% (80\%) with a positional accuracy of $500 \mathrm{~m}(1 \mathrm{~km})$ or better (Burrows et al., 2002; Dissing and Verbyla, 2003).

\subsection{Data integration}

In order to facilitate our analysis, the MODIS fire data and the lightning data points are geographically matched into the mesh of NARR grid boxes and summed for each day. As a result, the matching algorithm generates an integrated, gridded dataset that includes the means of each meteorological variable (derived from the 3-hourly NARR data), the total number of lightning strikes, and the Terra MODIS fire counts at each NARR grid box for each day. Several new variables important for discerning atmospheric regimes for igniting fires are then derived from the integrated dataset at each NARR grid box including: the number of dry and wet days, the number of dry and wet lightning strikes, and the daily maximum temperature (Table 2). Dry (wet) days are simply a running total of days for each NARR grid box where less than $2 \mathrm{~mm}$ ( $\geq 2 \mathrm{~mm}$ ) of precipitation is observed during the 24-h period. The dry (wet) day variable is set to zero when a grid box receives a precipitation amount $\geq 2 \mathrm{~mm}(<2 \mathrm{~mm})$. Similarly, dry (wet) lightning strikes are defined as any strike occurring in a NARR grid box that receives less than $2 \mathrm{~mm}(\geq 2 \mathrm{~mm}$ ) of precipitation for each daily time step. The $2 \mathrm{~mm}$ threshold used here is similar to that used in earlier studies (e.g. Hall, 2007; Rorig and Ferguson, 1999, 2001).

In contrast to earlier studies of dry lightning activity using precipitation data from scattered surface observations, this study allows for a unique, high-resolution dataset of dry lightning activity across the entirety of northern North America, regardless of population and instrument placement. However, the variety of data sources creates a concern for comparability, especially between observations (e.g. lightning strikes) and reanalysis output (e.g. precipitation). When generating precipitation fields, the NARR assimilates surface rain gauge observations (Mesinger, 2006). Therefore, the data quality is highest in regions with many observations and lower in regions with sparse observations. Despite sparse observations in boreal North America, results from Solaiman and Simonovic (2009) show a strong correlation $(R=0.77$ 0.97 ) between observed precipitation and NARR-generated precipitation in Ontario. Similarly, Choi et al. (2009) calculated a correlation coefficient of 0.74 using observations in Manitoba. Based on these studies, the NARR was chosen as the best source of precipitation data for the remote boreal forest. Any deviations from observations are usually negative simply because the NARR is on an aerial (model) grid rather than a single point location (Kim et al., 2008; Choi et al., 2009). In addition to the NARR, data comparison issues arise between the MODIS fire data and metrological data, especially if cloud cover exists at the time of a fire ignition. However, these situations will be accounted for in section 5.2 (when investigating the holdover effect).

\section{Large-scale analysis}

To provide a general representation of the meteorological factors responsible for the interannual variability of fire activity, the Pearson correlation coefficients $(R)$ are computed between the fire, lightning, and meteorological parameters for regions A and B based upon the seasonal-mean of the analysis variables in Table 2. To represent fire intensity, the average $F R P$ per fire pixel $\left(F R P_{\text {avg }}\right)$, and the regional $F R P$ flux $\left(F R P_{f}\right)$, defined as the total FRP divided by the total land area within each regional domain (Ichoku et al., 2008a), are also used. Following this analysis, only a few key meteorological variables stand out as statistically significant (Table 3 ), and they are analyzed comparatively and independently in each region (A and B).

\subsection{Role of moisture in fire variability}

In contrast to relative humidity (RH) and fire season precipitation, the derived consecutive dry days variable shows a relatively strong, positive correlation with fire counts and $F R P_{\mathrm{f}}$ in both regions with $R_{\text {firecount }}=0.63$ and $R_{F R P_{\mathrm{f}}}=0.57$ $\left(R_{\text {firecount }}=0.61\right.$ and $\left.R_{\text {FRPf }}=0.70\right)$ in region A (region $\left.\mathrm{B}\right)$. This result quantitatively supports the hypothesis made in earlier studies, with limited ground-based data (e.g. Flannigan and Harrington, 1988), that the role of the duration of dry conditions is far more dominant than the total precipitation in regulating the variation of seasonal fire activity. One likely 
Table 2. Analysis variables.

\begin{tabular}{llrl}
\hline & \multicolumn{1}{c}{ NARR Meteorological Variables } & & Lightning and Derived Variables \\
\hline 1 & Convective Precipitation & 18 & Total Number of Lightning Strikes \\
2 & Horizontal Moisture Divergence & 19 & Number of Dry Lightning Strikes \\
3 & 850hPa Wind Speed & 20 & Number of Wet Lightning Strikes \\
4 & November-May Snowfall & 21 & Number of Dry Days \\
5 & Fire Season Precipitation & 22 & Number of Wet Days \\
6 & November-May Precipitation & 23 & Daily maximum Temperature (10m) \\
7 & Relative Humidity (surface) & & \\
8 & Soil Moisture (0-200 cm) & & MODIS Variables \\
9 & Liquid Volume Soil Moisture (0-10 cm) & 24 & Fire Counts \\
10 & Canopy Water Content & 25 & Fire Radiative Power (FRP) \\
11 & 10m Temperature & & \\
12 & 10m Temperature (January-May) & & Derived from MODIS \\
13 & Lifted Index (LI) & 26 & Regional FRP flux \\
14 & Convective Available Potential Energy (CAPE) & 27 & Average FRP per fire pixel \\
15 & Turbulent Kinetic Energy (TKE) & & \\
16 & Precipitable Water & & \\
17 & 500hPa Geopotential Height & & \\
\hline
\end{tabular}

Table 3. Correlations for selected meteorological variables, fire counts, and FRP data ${ }^{1}$.

\begin{tabular}{|c|c|c|c|c|c|c|}
\hline \multirow[t]{2}{*}{ CORRELATIONS } & \multicolumn{3}{|c|}{ Region A. (ALASKA) } & \multicolumn{3}{|c|}{ Region B. (CANADA) } \\
\hline & Fire Counts & Regional FRP Flux & $\begin{array}{l}\text { Average FRP } \\
\text { per fire pixel }\end{array}$ & Fire Counts & Regional FRP Flux & $\begin{array}{l}\text { Average FRP } \\
\text { per fire pixel }\end{array}$ \\
\hline Total \# Lightning Strikes & $\underline{0.93}$ & $\underline{0.90}$ & -0.30 & -0.53 & -0.69 & 0.33 \\
\hline \# Dry Lightning Strikes & $\overline{\mathbf{0 . 7 3}}$ & $\overline{0.67}$ & -0.22 & -0.37 & -0.16 & 0.40 \\
\hline$\%$ Lightning Strikes as Dry & $-\overline{0.36}$ & -0.41 & -0.13 & -0.22 & -0.22 & 0.31 \\
\hline Nov-May Snowfall & 0.23 & 0.19 & 0.27 & -0.11 & -0.19 & -0.02 \\
\hline Fire Season Precipitation & -0.46 & -0.42 & -0.03 & -0.04 & -0.15 & -0.68 \\
\hline Nov-May Precipitation & -0.05 & -0.12 & -0.71 & 0.58 & 0.38 & -0.79 \\
\hline Total Dry Days per Grid Box & 0.63 & 0.57 & $\overline{-0.56}$ & 0.61 & $\underline{0.70}$ & $\overline{-0.22}$ \\
\hline Relative Humidity (sfc) & -0.42 & -0.40 & 0.08 & 0.20 & $\overline{0.00}$ & -0.69 \\
\hline CAPE & $\underline{0.97}$ & 0.96 & -0.41 & -0.67 & -0.73 & 0.48 \\
\hline $500 \mathrm{hPa}$ Height & 0.83 & 0.83 & -0.09 & 0.55 & 0.73 & -0.38 \\
\hline
\end{tabular}

${ }^{1}$ Correlation coefficient is computed from the seasonal averages of each variable.

Underlined values: $|R| \geq 0.70$; bold font: significance level: $90 \%$; italic font: significance level: $95 \%$.

explanation of this counter-intuitive result is that a fire season with ample precipitation may still be active if there is a long stretch of dry conditions between wet periods. Furthermore, the upper layer of soil and plant debris would be greatly affected by a long stretch of dry days, and the moisture at this particular layer is indeed the major moisture parameter considered in the Canadian Fire Weather Index (Amiro et al., 2004). However, when investigating the $F R P_{\text {avg }}$ of each individual fire count, only the precipitation prior to the start of the fire season (November-May) stands out with $R=-0.71$ and $R=-0.79$ in region $\mathrm{A}$ and region $\mathrm{B}$, respectively.

\subsection{Role of instability and lightning in fire variability}

Consistent with earlier studies (e.g. Skinner et al., 1999, 2002; Fauria and Johnson, 2006), the $500 \mathrm{hPa}$ geopotential heights display a positive relationship $(R=0.83)$ with the fire counts in region $\mathrm{A}$, suggesting that anomalously high $500 \mathrm{hPa}$ heights set the stage for active fire weather periods in this region. Three parameters affected by the $500 \mathrm{hPa}$ height pattern (the surface-based CAPE, total cloudto-ground lightning strikes, and total dry lightning strikes) are also immediately evident as important variables in region A with $R=0.97, R=0.93$, and $R=0.73$, respectively. Similar results are obtained when using the $F R P_{f}$, suggesting that 

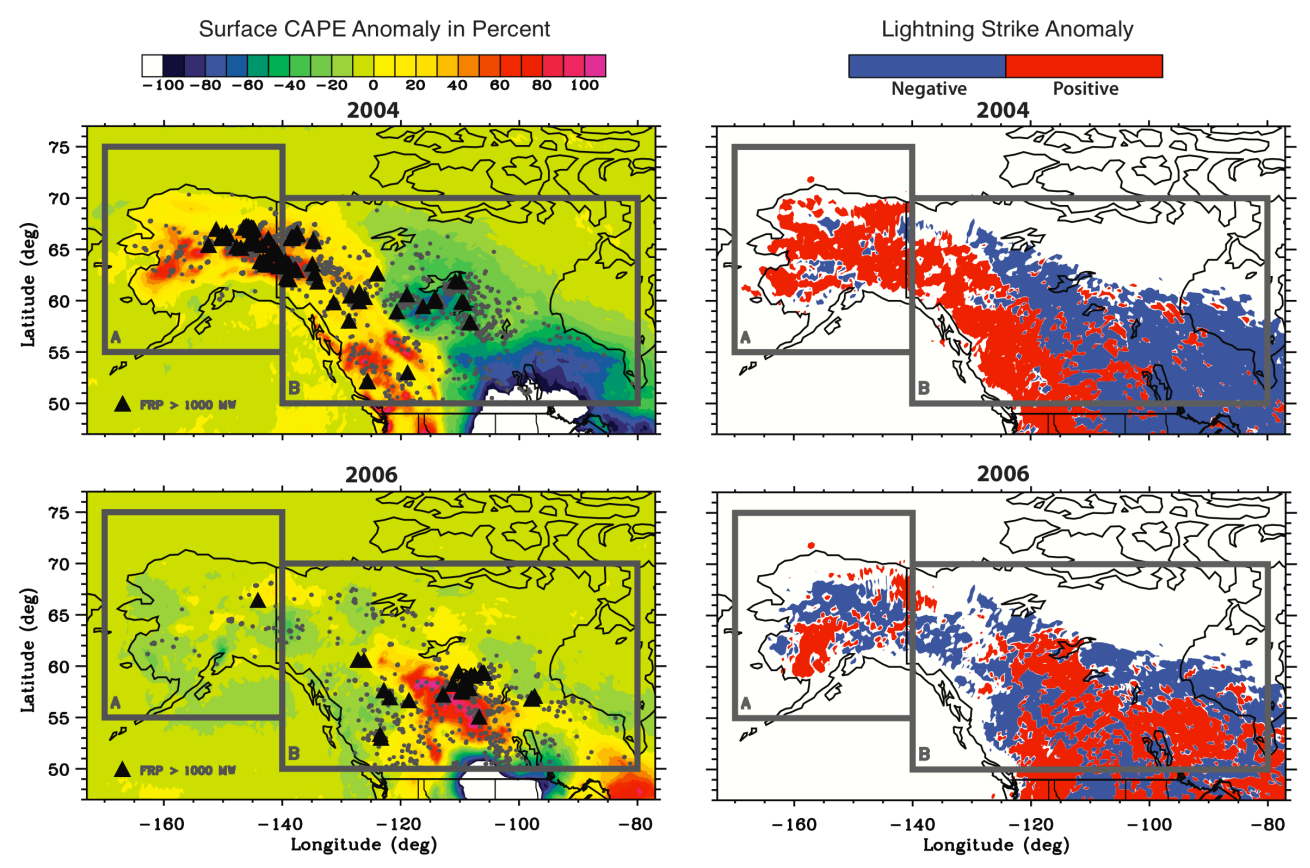

Fig. 2. (Left) Surface CAPE anomaly in percent (color filled) overlaid with MODIS fire data for the fire seasons of 2004 (top) and 2006 (bottom). The MODIS fire pixels are denoted as grey dots except those with FRP $>1000 \mathrm{MW}$ which are highlighted as black triangles. (Right) Positive and negative anomalies for total lightning strikes during the fire season of 2004 (top) and 2006 (bottom). All anomalies are based on the 7-year (2000-2006) study interval, and the regional study domains for Alaska and Canada (A and $\mathbf{B})$ are highlighted with grey boxes.

changes in instability and lightning activity associated with the large-scale pattern influence both the number and the intensity of fires in region A (Alaska).

Conversely, 500 hpa geopotential heights, instability (CAPE), and lightning strikes are weakly (or negatively) correlated with fire counts and $F R P_{f}$ in region B (Table 3). After close scrutiny, the unexpected results in region $\mathrm{B}$ are likely due to the height gradient between a ridge and a trough at $500 \mathrm{hPa}$ bisecting this region in the seasonal mean with a ridge present in the west and trough in the east (contours in Fig. 1). This pattern creates a highly variable environment with respect to geopotential height just east of the Canadian Rockies that does not allow a specific synoptic pattern to remain in place for long temporal durations (Skinner et al., 2002).

Geographical examples for interpreting the statistical results revealed in the above analysis are shown in Fig. 2. The fire season of 2006, which follows a traditional synoptic setup for an active fire season in central Canada (Skinner et al., 2002), conforms to the expectation that the distribution of anomalously high CAPE and lightning strikes will coincide with the highest concentration of fire counts and high FRP values ( $>1000 \mathrm{MW})$. In contrast, there is an unconformity in central Canada immediately east of the Rocky Mountains during the fire season of 2004, the most active fire season of the seven-year study period in both region A and B. Previous studies have shown similar examples where a certain amount of fire activity occurs within the trough in the seasonal $500 \mathrm{hPa}$ height mean (e.g. Skinner et al., 2002) suggesting that the $500 \mathrm{hPa}$ height is not a perfect tool for assessing fire variability under certain synoptic environments in every region of the boreal forest. Therefore, it is also obvious that discrepancies may exist between the meteorological setups producing the dry lightning events that ultimately ignite fires across the boreal forest.

\section{Focused sub-regional analysis}

While the large-scale analysis (regions A and B) in the previous section is helpful toward a general understanding of the effects of the synoptic pattern on fire activity, a finer spatial (eastern and western domains) and temporal (daily) analysis is necessary for understanding the meteorological factors favorable to lightning activity and ultimately, the fires. In addition, both Fig. 2 and Table 3 in the previous section reveal that the meteorological factors (such as: $500 \mathrm{hpa}$ geopotential height, CAPE, and total lightning strikes) considered as important for fire ignition showed little correlation with the average FRP per fire pixel. With lightning activity recognized as the major cause of boreal fire ignition, the following sub-regional analysis focuses on the meteorological influences on lightning activity and its effect on the variation of fire counts. Detailed analysis of meteorological variables 


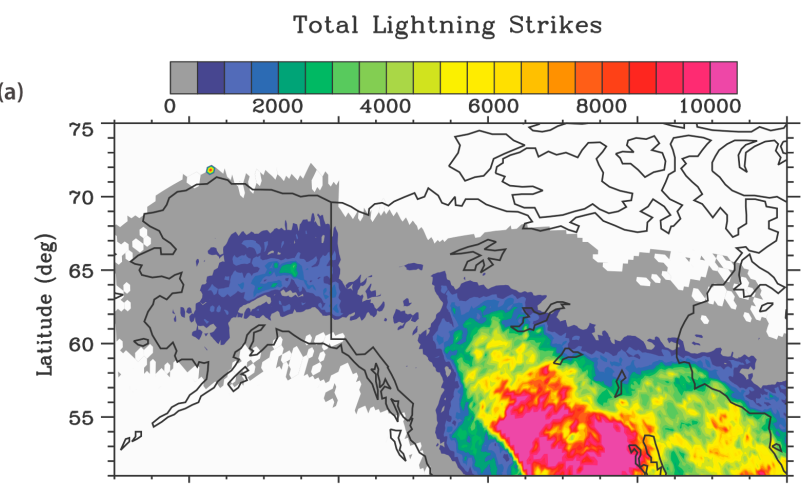

Number of Fire Counts

(b)

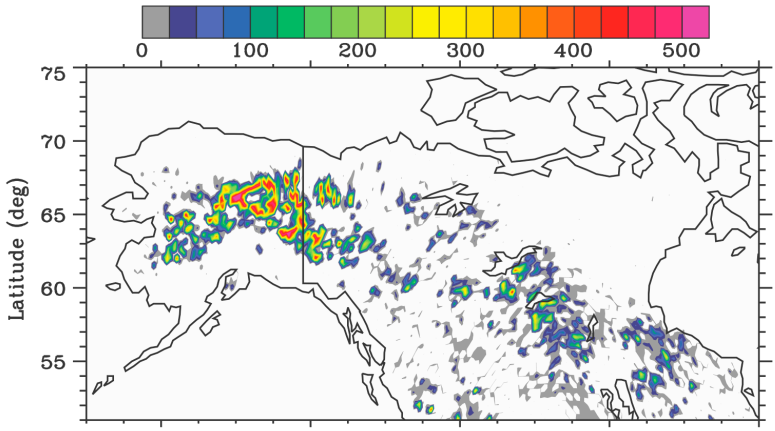

Percent Lightning Strikes as Dry

(c)

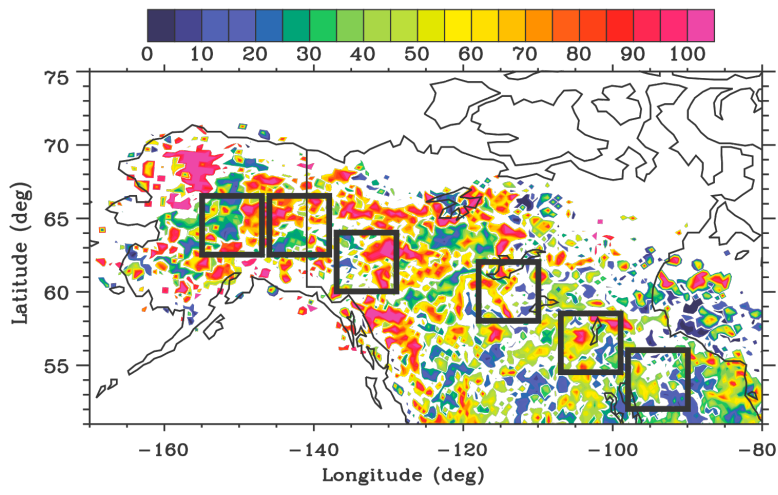

Fig. 3. (a) Total lightning strikes per grid box, (b) total fire counts per grid box, and (c) the percentage of lightning strikes occurring as dry strikes per grid box for the fire seasons of 2000-2006. The six boreal focus regions composing the western and eastern domains are displayed in black in (c) and are consistent with Fig. 1. White color indicates locations with no valid data.

and their effects on fire intensity $\left(F R P_{f}\right.$ and $\left.F R P_{\text {avg }}\right)$ will be left for a future study.

\subsection{Spatial and temporal variation of lightning and fire counts}

Figure $3 \mathrm{a}$ shows the total number of lightning strikes per NARR grid box observed during the 7-year study period, indicating a general increase of lightning activity from the coast to the interior regions of Canada and Alaska especially in the southern portions of the boreal forest. Quantitatively, the general location of the eastern domain experiences much more lightning activity (often 2000-6000 strikes per grid box) than the western domain (often 500-2000 strikes per grid box). However, the western domain does coincide with a local maximum of lightning activity in interior Alaska and Canada. The distribution of total fire counts in each NARR grid box (Fig. 3b) shows the opposite pattern as that for lightning (Fig. 3a). Specifically, the majority of grid boxes in the western domain experienced $\sim 400-500$ fire counts during the seven-year study time period while only a few grid boxes in the eastern domain approached 300 fire counts.

To study the difference in spatial patterns between Fig. 3a and $b$, the distribution of the percentage of lightning strikes occurring as dry strikes per grid box is computed (Fig. 3c). Interestingly, dry strikes, which have been found to be the dominant driver of fire variability in the boreal forest (Boles and Verbyla, 2000; Stocks et al. 2002), are only a small portion of the total lightning activity. For example, only $23 \%$ $(21 \%)$ of all observed lightning strikes are dry in the western (eastern) domain. From a monthly perspective, 27-31\% (23$24 \%$ ) of lightning strikes are dry in June and August while only $17 \%(18 \%)$ are dry in July for the western (eastern) domain. The interannual variability of dry lightning activity ranges from a minimum of $17 \%(13 \%)$ to a maximum of $35 \%(26 \%)$ in the western (eastern) domain.

Geographically, the western domain contains the highest percentage of dry lightning strikes with several individual grid boxes greater than $80 \%$. These localized values are much higher than the averaged percentage of dry strikes in the western domain as a whole (23\%) because there are many more grid boxes with less than $40 \%$ dry strike activity. Therefore, localized influences, such as topography, likely affect the distribution between high percentage and low percentage dry strike grid boxes. Previous work has shown a positive relationship between total lightning strikes and elevation (Reap, 1991; Dissing and Verbyla, 2003), but the effect of topography on only dry strikes is still unclear.

Regardless of potential topographical influences, the western and eastern boreal domains contain a greater quantity of grid boxes with a high percentage of dry strikes than nonforested locations to the south. In addition, the individual grid boxes (within the eastern and western domains) with a high percentage of dry strike activity commonly experience a greater number of fire counts over the seven-year study period. Hence, while the average percentage of dry strikes is low in both the eastern and western domain, the percentage of dry strikes per grid box qualitatively appears to reconcile the discrepancies between total lightning strikes (Fig. 3a) and fire activity (Fig. 3b). 


\subsection{Temporal segment correlations and holdover effect analysis}

While Fig. 3 is consistent with the large-scale analysis in Table 3 suggesting that lightning activity is positively correlated with fire counts in the western domain but not in the eastern domain, it is worth noting that such correlation analysis is done at the seasonal scale using averages over large regions (A and $\mathrm{B}$ ) where considerable portions are not covered by the boreal forest. To further study the lightning effects on fire ignition, the following two questions become relevant: (1) Does the same correlation contrast between west and east (shown in Table 3) change at varying time scales when focusing on smaller regions of the eastern and western domains? (2) How does the post-ignition lag (holdover) time between the lightning ignition and satellite detection of the fire affect the ratio of lightning vs. fire counts?

To address the first question, a temporal segment correlation analysis is conducted by dividing the fire season (92 days) into a series of temporal segments (ranging from 3-92 days) with an equal length of days for each year. Using the seven years of data, the correlation coefficients between fire counts and dry, wet, and total lightning strikes are then computed based upon the averages over each individual temporal segment in both the eastern and western domains (Fig. 4a, b). It is expected that such a correlation should increase as the length of the segment reaches the total number of days for the season and hence, many localized (and somewhat random) processes will be averaged out to allow the dominant mechanisms for the interannual variability to stand out.

The western domain follows the expected result nicely with R-values increasing from 0.20 at segment length of 9 days to 0.80 at the seasonal cutoff (Fig. 4a). However, the eastern domain deviates from the expectation after the 15day division with $\mathrm{R}$ approaching -0.60 by the seasonal cutoff (Fig. 4b). This result is likely related to the mechanisms responsible for lightning activity in each domain. In the western domain, prolific lightning activity only occurs in active fire years because this is when the large-scale pattern becomes conducive to enhanced thunderstorm development in these high latitudes by allowing low-level instability (CAPE) to increase dramatically (Skinner et al., 1999; Dissing and Verbyla, 2003). Furthermore, the synoptic pattern displays limited fire season variability in the region encompassing the western domain (Skinner et al., 2002), suggesting that a fireconducive pattern will remain in place for relatively long durations.

In contrast, the eastern domain, located at lower latitudes, experiences a great deal of lightning activity in every season in association with both unstable air mass events and large frontal disturbances. During an active fire season, the frequency of large frontal disturbances decreases due to an increased presence of positive $500 \mathrm{hPa}$ height anomalies (Skinner et al., 1999, 2002) and isolated, instability driven thunderstorms likely dominate. Therefore, the total number
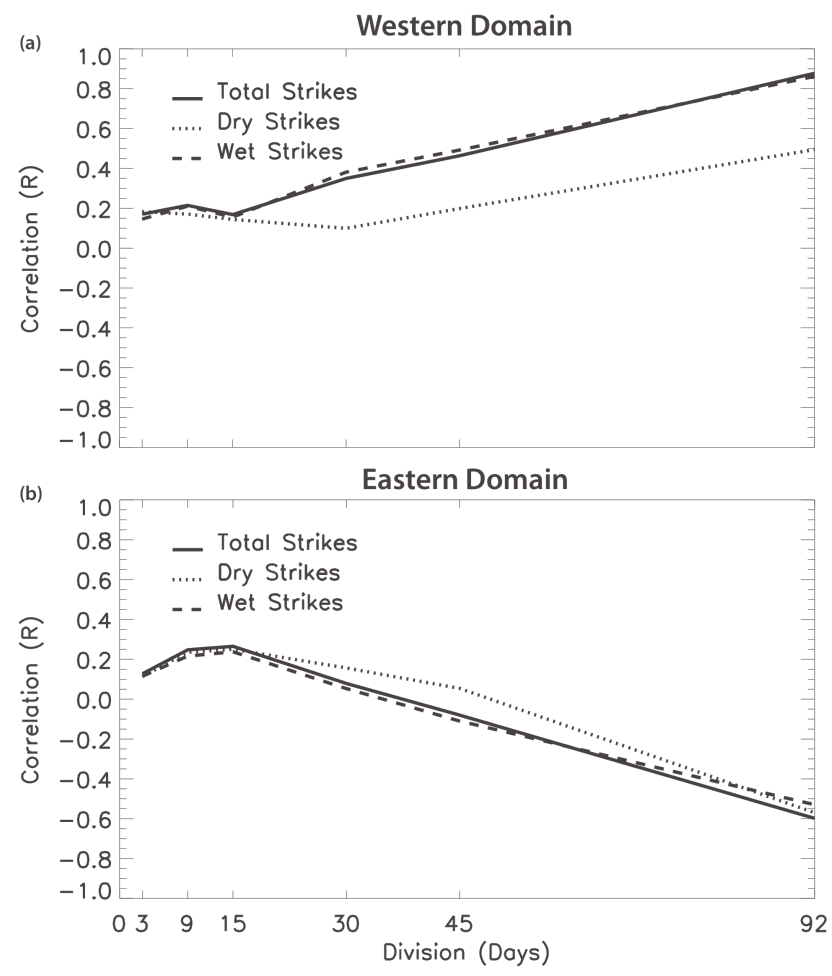

Fig. 4. Correlation coefficients between fire counts and total, wet, and dry lightning strikes computed as a function of the length of temporal segments (ranging from 3 to 92 days) in the western domain (a) and the eastern domain (b). The data time series used in the calculation consists of daily-paired fire and lightning data in JuneAugust (92 days) of 2000-2006. Please see Sect. 5.2 for details.

of lightning strikes and low-level moisture availability decreases but the number of fires (ignited by lightning) subsequently increases. As observed in the large-scale analysis and previous studies (e.g. Skinner et al., 2002), the eastern domain is located in a highly transient synoptic environment allowing for more monthly variations than the western domain. Therefore, many fire-conducive patterns will remain in place for only a few days to a few weeks, helping to explain the negative correlation after the 15-day division. This analysis builds on the large-scale results (region B) and shows that there are many complexities with lightning activity and fire ignition in the smaller eastern domain. It is very likely that a fire will be ignited during short-lived, but favorable, dry lightning conditions and will burn during the days following the synoptic pattern change. This seems to be especially true when positive height anomalies persist in western North America such as during the fire season of 2004 (Fig. 2). Therefore, it is also possible that some of these lightning-caused fires will be extinguished when the pattern shifts and less favorable burning conditions exist.

Another complicated factor for interpreting the inconsistency between spatial distribution of fire counts and lightning strikes is the time lag between the actual strike and the 


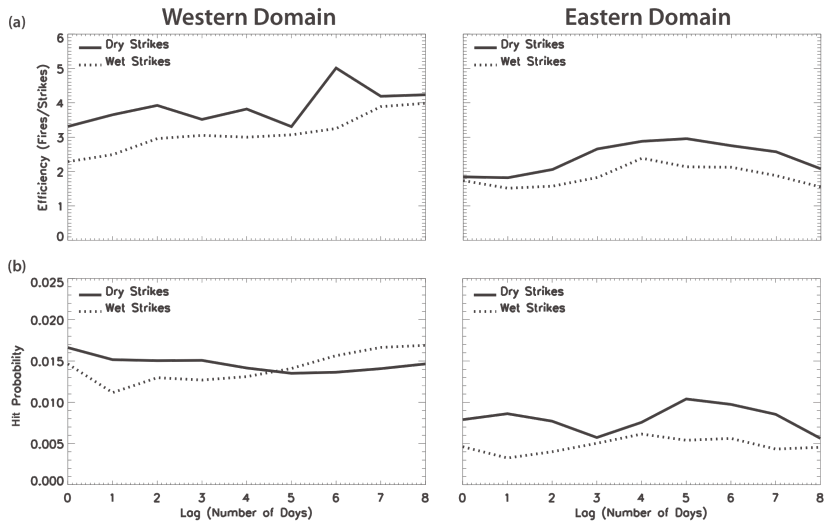

Fig. 5. (a) Efficiency of dry and wet lightning strikes in fire ignition for the western domain (left) and the eastern domain (right). (b) Same as (a) but for the hit probability of a fire ignition associated with a dry or wet lightning strike within a grid box.

fire start (question 2 raised in the beginning of this subsection). This lag effect, also known as the holdover effect, results from the time it takes for a fire, which may smolder for several days or is obscured cloud cover, to become substantial enough (or in clear-sky conditions) to be observed by either satellite or ground observations following the strike. It has been suggested that these holdover fires can take as long as 7-10 days to become visible when using surface observation techniques in the remote boreal forest (Flannigan and Wotton, 1991). When using MODIS data, this time may be reduced (in remote areas), but it will not be completely removed because fire detection is difficult in cloudy conditions (whose likelihood is small under positive height anomalies). In the western (eastern) domain the average number of fires per dry strike is about $0.50(0.04)$ and $0.15(<0.01)$ for wet strikes without accounting for the holdover effect.

To address the actual holdover effect, two parameters, the efficiency $(E)$ of lightning strikes in producing fires and the "hit" probability of lightning with fires $(H P)$ are computed for each NARR grid as a function of lag time. Specifically, $E_{\text {dry }}$ and $E_{\text {wet }}$ are computed as the number of fire counts divided by the number of dry or wet lightning strikes. HP values for dry and wet lightning $\left(H P_{\text {dry }}\right.$ and $\left.H P_{\text {wet }}\right)$ are computed through a "hits-and-misses" technique. For example, dry hits $\left(H_{\text {dry }}\right)$ occur when a fire count and dry lightning strike are observed together in a grid box and dry misses $\left(M_{\text {dry }}\right)$ occur when only dry lightning is observed in a grid box. $H P_{\text {dry }}$ is simply the ratio of $H_{\text {dry }}$ with the sum of $H_{\text {dry }}$ and $M_{\text {dry }}$. Using a similar procedure, $H P_{\text {wet }}$, the counterpart of $H P_{\mathrm{dry}}$, can also be computed. Each parameter $\left(E_{\mathrm{dry}}\right.$, $E_{\text {wet }}, H P_{\text {dry }}$, and $\left.H P_{\text {wet }}\right)$ is computed using the available data from 2000-2006 for each NARR grid box. However, any grid boxes with neither fires nor lightning are disregarded. The averages of the valid results at each grid box over the eastern and western domains are shown in Fig. 5 using fire count lag times of 1 to 8 days.
As expected, the averaged $E_{\mathrm{dry}}$ and $H P_{\mathrm{dry}}$ are higher than $E_{\text {wet }}$ and $H P_{\text {wet }}$ in both domains. However, the $E_{\text {wet }}$ and $H P_{\text {wet }}$ values are greater than zero in both domains suggesting that wet strikes, presumably associated with precipitation amounts just above $2 \mathrm{~mm}$, may also play a role in fire ignition. This "wet" influence would be most common with lightning striking away from the main precipitation shield or with dying thunderstorms. Regardless of lag, $E_{\text {dry }}$ in the western domain is higher than the eastern domain with values of about 4 and 2.5 fires per dry strike respectively. Therefore, the chance of a dry lightning strike igniting a fire in the western domain is a factor of $\sim 1.5$ higher than the eastern domain. Similarly, $H P_{\text {dry }}$ is also higher in the western domain.

It was expected that the efficiency and hit probability lag plots would show a distinct peak at the optimal lag needed to account for the holdover effect. However, the hit probability analysis $\left(H P_{\text {dry }}\right)$ does not show a trend based on lag in either domain (Fig. 5b). Therefore, the holdover effect is based solely on the efficiency profiles $\left(E_{\mathrm{dry}}\right)$. For example, the eastern domain shows a distinct increasing trend in $E_{\text {dry }}$ until lag 3 (Fig. 5a) suggesting that a lag of 3 days must be accounted for. In contrast, the $E_{\text {dry }}$ profile for the western domain contains a lot of variation and does not show a specific trend based on lag. Therefore, a lag of 2 days seems sufficient to account for holdovers. This assumes that fires become detectable slightly faster in the western domain than the eastern domain, which could be related to the meteorological discrepancies affecting the plots in Fig. 4. To further account for possible on-going fires, the calculations used to produce Fig. 5 were also performed by applying running means of $2-5$ days to the fire data prior to the efficiency and hit probability calculations. However, any influence on $E_{\text {dry }}, E_{\text {wet }}$, $H P_{\text {dry }}$, or $H P_{\text {wet }}$ from this on-going fire effect was found to be negligible (results not shown).

While a detailed lag-analysis is conducted above to account for holdover fires, the exact time of a fire start remains a mystery even with daily satellite observations in clear conditions, not to mention in cloudy conditions. If meteorological data with a smaller grid size becomes available, it is possible that even this resolution will be too coarse to capture exact meteorological factors for isolated lightning events and to establish cause vs. effect. There is also a chance, although small, that fires may propagate from one model grid box to another. Several modeling techniques have been developed to resolve the holdover fire effect at relatively small spatiotemporal scales (e.g. Anderson, 2002; Wotton and Martell, 2005). However, this study, which takes place at much larger spatial and temporal scales, requires a general holdover time specific to MODIS observations for each study domain. Due to the fact that precise scenarios for each individual fire are difficult to obtain, our results are statistical in nature, as shown in this section and the following section, by analyzing the large dataset to discern dominant mechanisms. 

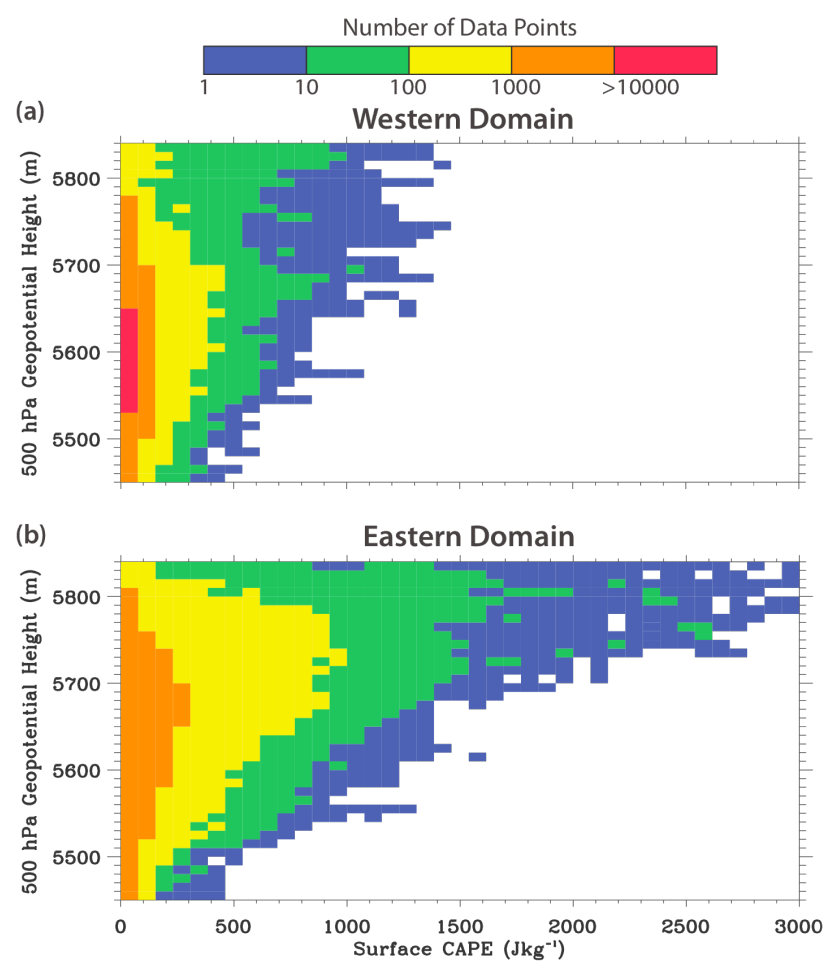

Fig. 6. Joint number (of data points) distribution of CAPE and the $500 \mathrm{hPa}$ geopotential height for the western domain (a) and the eastern domain (b). White areas do not contain observed data.

\section{Grid-based joint probability analysis}

The final analysis builds upon the previous Sects. 4 and 5 to study the meteorological influence on the lightning-related fire variability in the boreal forest through a three-step investigation: (1) the probability of dry and wet lightning occurrence as a function of the contributing meteorological variables found in the large-scale analysis, (2) the meteorological regimes favorable for lightning to ignite a fire, and (3) a comparative analysis between the eastern and western domains. To study these factors, a joint probability analysis for fire counts and lightning as a function of meteorological variables is conducted for the daily gridded dataset (native NARR grid of $32 \mathrm{~km}$ ) with a total of 700,000+ data pairs when considering the seven years of data.

\subsection{Meteorological factors associated with lightning activity}

Based on the large-scale analysis (section 4), CAPE and $500 \mathrm{hPa}$ geopotential height anomalies have a distinct influence on fire activity. However, to better explain their impacts on fire activity, the effect of these variables on lightning activity, the presumable cause of most fires in the western and eastern domains, must be investigated. To begin, the range of the observed $500 \mathrm{hPa}$ height and CAPE data are each divided equally into $\sim 20$ bin boxes per variable. This forms a mesh of $\sim 400$ bin boxes with $500 \mathrm{hPa}$ heights in one dimension and CAPE in another dimension. The available data points, derived from each NARR grid box over the seven-year interval are mapped into bin boxes on the mesh based upon their corresponding values of $500 \mathrm{hPa}$ height and CAPE.

By tallying the available NARR grid boxes in each bin box $\left(\mathrm{N}_{x y}^{\text {tot }}\right)$, the joint number density distribution of data points based on CAPE (subscript $x$ ) and $500 \mathrm{hPa}$ heights $(y)$ can be ascertained (Fig. 6). In the eastern domain, the distribution of $N_{x y}^{\text {tot }}$ covers a much larger range of CAPE values $\left(0-3000 \mathrm{Jkg}^{-1}\right)$ than the western domain $\left(0-1400 \mathrm{Jkg}^{-1}\right)$. In addition, there are many days during the fire season lacking convective activity. Therefore, the majority of $N_{x y}^{\text {tot }}$ are associated with relatively low CAPE values of less than $200 \mathrm{Jkg}^{-1}\left(700 \mathrm{Jkg}^{-1}\right)$ in the western (eastern) domain. The influence of latitudinal location is also evident with a shift toward slightly higher $500 \mathrm{hPa}$ heights in the eastern domain.

Similar to $N_{x y}^{\text {tot }}$, the data points with dry or wet lightning occurrence are tallied $\left(L_{x y}^{d}\right.$ and $\left.L_{x y}^{w}\right)$ and the individual dry or wet lightning strikes occurring within the NARR grid boxes of $L_{x y}^{d}$ and $\mathrm{L}_{x y}^{w}$ are summed $\left(S_{x y}^{d}\right.$ and $S_{x y}^{w}$ ). This allows the average number of dry or wet lightning strikes occurring in a given NARR grid box $\left(A_{x y}^{d}\right.$ and $A_{x y}^{w}$ ) to be computed for each bin box on the mesh: $A_{x y}^{d}=S_{x y}^{d} / L_{x y}^{d}$ and $A_{x y}^{w}=S_{x y}^{w} / L_{x y}^{w}$ (Fig. 7). As would be expected with lightning activity, the representative CAPE values for both the largest $A_{x y}^{d}$ and $A_{x y}^{w}$ increase from those in Fig. 6 to $500 \mathrm{Jkg}^{-1}$ and $1000 \mathrm{Jkg}^{-1}$ in the western and eastern domain, respectively. The corresponding levels of $500 \mathrm{hPa}$ height are 5600 meters and $5700 \mathrm{~m}$ in the western domain and eastern domain, respectively.

Based on Figs. 6 and 7, the probability of dry and wet lightning occurrence $\left(P_{x y}^{d}\right.$ and $\left.P_{x y}^{w}\right)$ is also computed for each bin box: $P_{x y}^{d}=L_{x y}^{d} / N_{x y}^{\text {tot }}$ and $P_{x y}^{w}=L_{x y}^{w} / N_{x y}^{\text {tot }}($ Fig. 8$)$. In the eastern domain, the highest $P_{x y}^{d}$ (e.g. $>50 \%$ ) is associated with CAPE values greater than $1500 \mathrm{Jkg}^{-1}$ and $500 \mathrm{hPa}$ geopotential heights greater than about $5700 \mathrm{~m}$. In contrast, a high $P_{x y}^{d}$ in the western domain is observed with much lower levels of CAPE and $500 \mathrm{hPa}$ geopotential heights with minimum values of $300 \mathrm{Jkg}^{-1}$ and $5450 \mathrm{~m}$, respectively. The lower values are likely a result of the higher latitudinal location and topographic effects that may allow for localized convergence and enhanced updrafts that would otherwise not produce a thunderstorm. However, even with latitudinal and possible topographic influences, the highest $P_{x y}^{d}$ in both domains is only found near the maximum observed range of CAPE values for each corresponding level of $500 \mathrm{hPa}$ geopotential height (grey shading in Fig. 8). Furthermore, the isolated nature of many dry thunderstorm events highlights the potential for a strong capping inversion that must be overcome with only a few updrafts growing strong enough to become a thunderstorm (Flannigan and Wotton, 1991; Rorig 

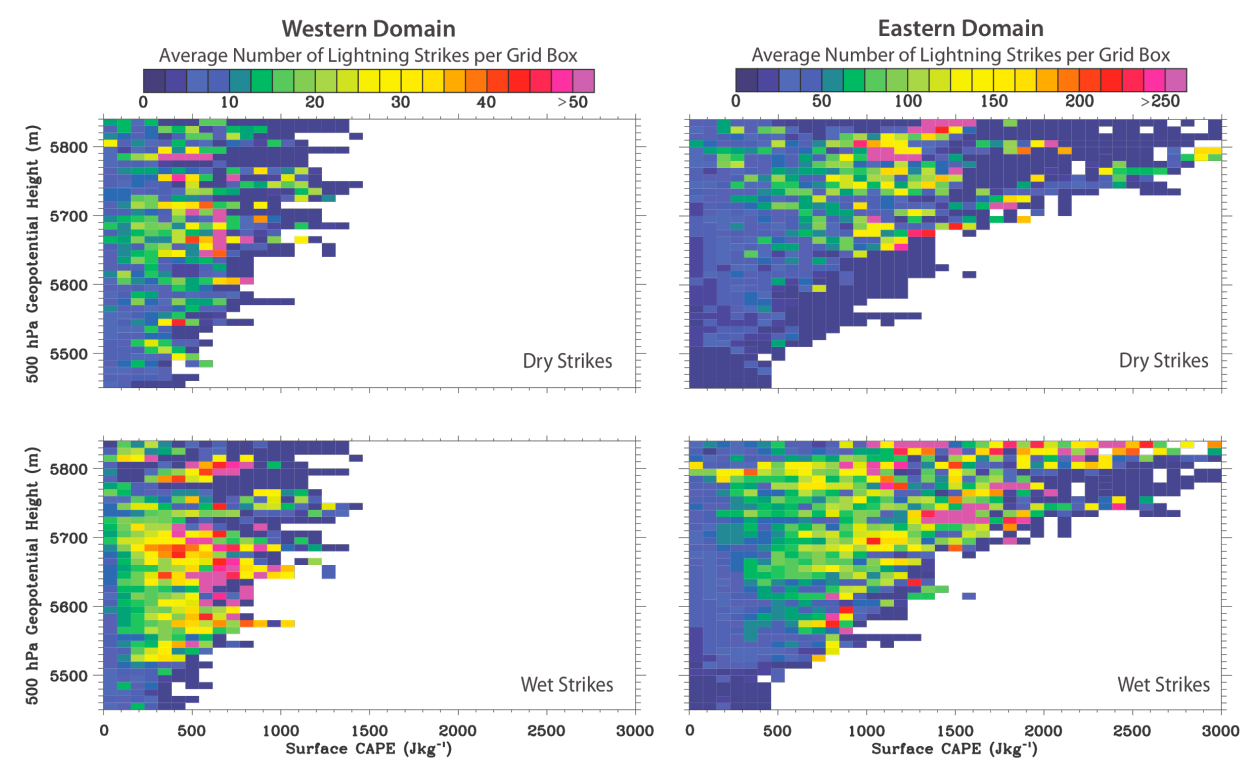

Fig. 7. The average number of lightning strikes (dry and wet) per grid box as a function of CAPE and $500 \mathrm{hPa}$ geopotential heights for the western domain (left) and the eastern domain (right). White areas do not contain observed data and the values of the western domain color bar are $1 / 5$ of the values in the eastern domain color bar.
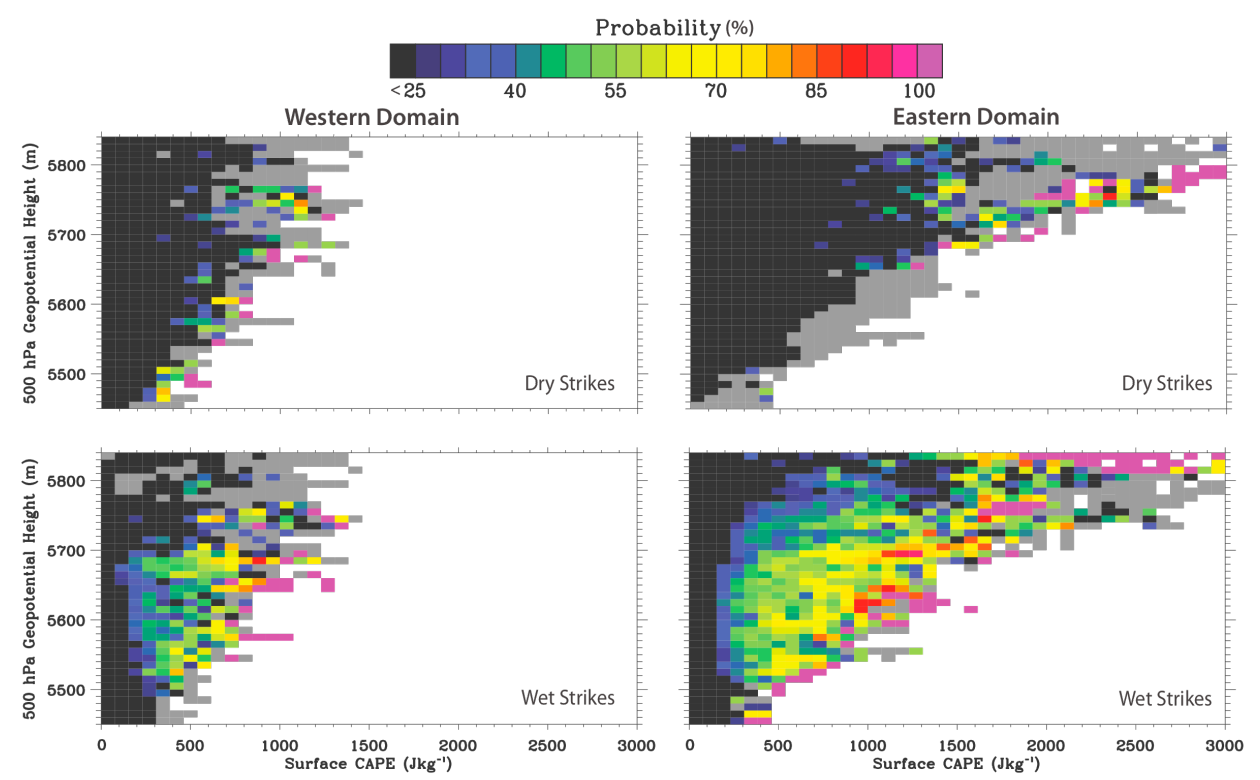

Fig. 8. Averaged probability of lightning activity (dry or wet) occurring within a grid box as a function of CAPE and $500 \mathrm{hPa}$ geopotential heights for the western domain (left) and the eastern domain (right). The observed CAPE and height values for 2000-2006 with a probability of dry lightning occurrence $\geq 25 \%$ are shaded in color, values with a probability of dry lightning occurrence between 0 and $25 \%$ are shaded in black, values without lightning occurrence are shaded in grey, and white areas do not contain observed data.

and Ferguson, 1999; Hall, 2007). This explains why the highest potential for dry thunderstorm activity is associated with the most extreme values of low-level instability. Therefore, the knowledge of representative CAPE values for each $500 \mathrm{hPa}$ height level in each domain, as shown in Fig. 8, can aid in forecasting these events.
While there are distinct limits on CAPE and $500 \mathrm{hPa}$ height for dry lightning strikes, wet lightning strikes are common in a variety of synoptic and thermodynamic environments in both domains. For example, high $P_{x y}^{w}$ values are found with similar CAPE and $500 \mathrm{hPa}$ height values as $P_{x y}^{d}$. However, high $P_{x y}^{w}$ values also exist with much lower 

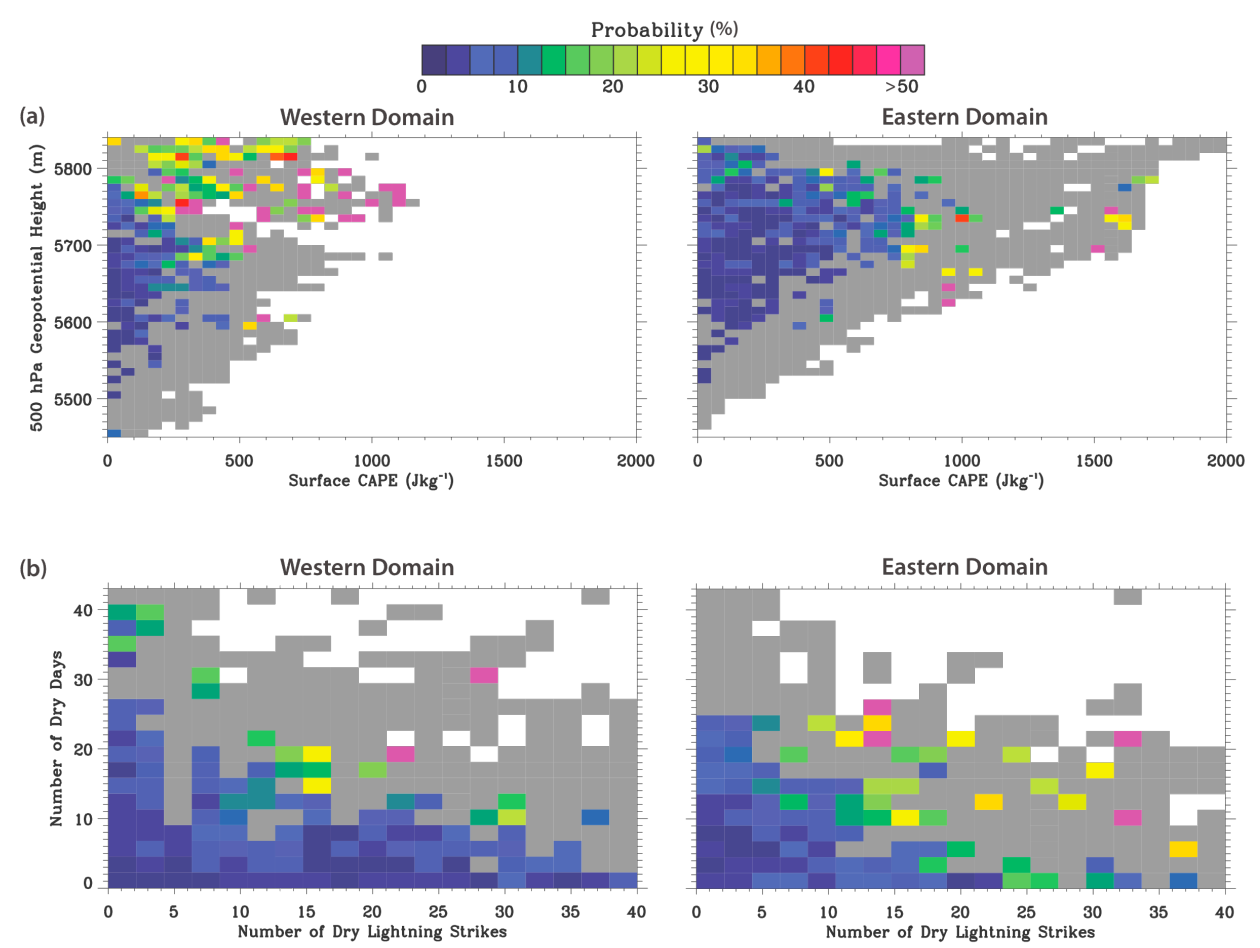

Fig. 9. (a) Probability of dry lightning strikes igniting a fire in a grid box based on CAPE and $500 \mathrm{hPa}$ geopotential heights with a holdover (lag) effect of 2 days in the western domain (left) and 3 days in the eastern domain (right). The observed CAPE and height values associated with fire ignition for 2000-2006 are shaded in color based on probability, observed values not associated with fire ignition are shaded in grey, and white areas do not contain observed data. (b) Same criteria as (a) but for but for the probability of a fire ignition in a grid box based on the number of dry lightning strikes and the number of consecutive dry days.

instability and heights. This large range is likely a result of many wet events occurring along frontal boundaries where $500 \mathrm{hPa}$ heights are lower, thus reducing the maximum observed levels of CAPE. Many of these events are also associated with large convective complexes rather than isolated thunderstorm activity thereby, reducing the chance of fire ignition (Flannigan and Wotton, 1991).

\subsection{Meteorological conditions favorable for lightning related fire activity}

With an understanding of the conditions associated with dry lightning activity, the meteorological conditions necessary for dry lightning strikes to actually ignite a fire are scrutinized. To begin, the holdover effect is accounted for by using a 2-day averaging period in the western domain and a 3-day averaging period in the eastern domain (as suggested in section 5.2). Using a method similar to the joint probability analysis in Fig. 8, the probability of dry lightningignited fires occurring in each grid box $\left(P_{x y}^{f d}\right)$ is then computed for all observed values of CAPE and $500 \mathrm{hPa}$ geopotential height in both the eastern and western domains for 2000-2006. However, the probability calculation in this case (Fig. 9a), uses the hit probability (hits-and-misses) technique described in section 5.2 for each bin box. In this case, CAPE also serves a secondary purpose by affecting the potential for fire ignition to be successful. Previous studies have highlighted the importance of unstable conditions to stronger entrainment of the air near the fires and faster spread rate (e.g. Werth and Ochoa, 1993).

As discovered in the lightning activity analysis (Fig. 8), the representative values for CAPE and the $500 \mathrm{hPa}$ geopotential height necessary to produce dry lightning in the western domain are $300 \mathrm{Jkg}^{-1}$ and 5450 meters respectively. However, the values corresponding to a high $P_{x y}^{f d}$ are about $300 \mathrm{Jkg}^{-1}$ and 5700 meters respectively (Fig. 9a). Therefore, it seems the dry strikes occurring with $500 \mathrm{hPa}$ heights below 5700 meters have a very low probability to produce fires in this region. Furthermore, CAPE values greater than $300 \mathrm{Jkg}^{-1}$ and $500 \mathrm{hPa}$ heights above $5700 \mathrm{~m}$ result in a $P_{x y}^{f d}$ of $15 \%$ to more than $50 \%$. While showing a similar trend, the same association of dry lightning with fire ignition in the eastern domain is not as strong with the maximum $P_{x y}^{f d}$ only reaching above $50 \%$ in a few bin boxes. In this domain, CAPE values greater than $800 \mathrm{Jkg}^{-1}$ and $500 \mathrm{hPa}$ heights at or above $5600 \mathrm{~m}$ provide the best chance of fire ignition from dry lightning. These values are lower than the CAPE threshold of $1500 \mathrm{Jkg}^{-1}$ and the $500 \mathrm{hPa}$ height threshold of $5700 \mathrm{~m}$ determined earlier for a high probability of dry lightning activity (Fig. 8). 
To complete the fire ignition analysis, two additional factors must be considered: (1) the total number of dry strikes necessary for a high chance of fire ignition and (2) fuel moisture. From the large-scale analysis used here (section 4), the number of consecutive dry days stands out as the moisture parameter commonly associated with a large number of fires. To address (1) and (2) the probability analysis is again performed using the total number of dry lightning strikes (subscript $x$ ) and the total number of consecutive dry days $(y)$ in place of CAPE and $500 \mathrm{hPa}$ height, respectively. In this case, the total number of grid boxes with fire occurrence $\left(\mathrm{F}_{x y}\right)$ and the total number of available grid boxes $\left(\mathrm{N}_{x y}^{\text {tot }}\right)$ over the sevenyear study period are used to compute the probability $\left(P_{x y}\right)$ for each bin: $P_{x y}=F_{x y} / N_{x y}^{\text {tot }}$ (Fig. 9b).

In both the eastern domain and western domain, the probability of fire ignition within a grid box is highest after 10-15 consecutive dry days and 10-15 dry lightning strikes; this probability approaches $\sim 50 \%$ after more than 20 dry days and/or more than 20 dry strikes. It seems that 10 consecutive dry days is an important consideration for fire potential. If there has been less than 10 consecutive dry days, the probability of a fire occurring in a given grid box is very low in both domains. Fauria and Johnson (2006) showed the importance of $500 \mathrm{hPa}$ height anomalies persisting for $10 \mathrm{consec}-$ utive days. However, from this analysis, it seems the consecutive dry days variable may be a better indicator of fire variability than $500 \mathrm{hPa}$ heights in the transient eastern domain because it is not necessarily affected by changes in the synoptic pattern (e.g. dry frontal passages).

\section{Summary and conclusions}

This study has provided a quantitative assessment of the meteorological environment favorable to lightning development and its influence on fire variability as observed by MODIS in the boreal forest of North America, using an integrated statistical approach with gridded datasets. Emphasis is on the understanding of meteorological factors such as CAPE and $500 \mathrm{hPa}$ heights favorable for wet and dry lightning to cause fires, although several other fire-related meteorological variables (including: number of dry days, relative humidity, and pre-fire-season precipitation) have also been analyzed to varying levels of detail. The primary step to understanding fire variability begins with the analysis of conditions necessary for dry lightning to occur and the spatial distribution of dry lightning activity across the North American boreal forest belt. While dry lightning is paramount, the results here suggest that wet strikes have an impact, though minor, on fire ignition as well.

Atmospheric instability (CAPE), lightning strikes, and positive anomalies in the $500 \mathrm{hPa}$ geopotential height field were found to explain more than $60 \%$ of the interannual variability in the number of fire counts in Alaska (A) while meteorological influences in the large Canada region (B) are very complex, especially east of the Canadian Rockies. At smaller spatial scales, there are clear differences in lightning activity between the mountainous western and the relatively flat eastern boreal forest study domains. For example, there is a greater chance of a lightning strike occurring as a dry strike and a higher chance that the strike will result in a fire for any given grid box in the western domain. Even though the eastern domain experiences many more lightning strikes per grid box than the western domain, the mechanisms behind lightning occurrence are different, with the western (eastern) domain showing a positive (negative) correlation between fires and lightning strikes. Furthermore, the efficiency of dry strikes in producing fires is nearly $50 \%$ lower in the eastern domain.

Deviations in the synoptic pattern $(500 \mathrm{hPa}$ heights $)$ and low-level instability (CAPE) stand out as key components to lightning variability in these regions which influences wildfire ignition and variability. In the western domain, a $15 \%$ to more than $50 \%$ chance of a fire being ignited by dry lightning exists for CAPE values greater than $300 \mathrm{Jkg}^{-1}$ and $500 \mathrm{hPa}$ heights above 5700 meters. In the eastern domain, the CAPE threshold changes to $800 \mathrm{Jkg}^{-1}$ and the $500 \mathrm{hPa}$ height threshold actually decreases to $5600 \mathrm{~m}$. The maximum chance of fire ignition is also weaker reflecting the low efficiency values calculated for the eastern domain. Reasons for this discrepancy are currently unclear, but an explanation may come from the differences in overall meteorological pattern and/or the biomass itself in this domain. Regardless of location, dry lightning strikes only occur near the maximum observed levels of CAPE for any given value of $500 \mathrm{hPa}$ height. Therefore, as recognized in the Haines index (Haines, 1988), low-level instability is a key factor in fire ignition in the boreal forest.

Following an investigation of many moisture variables and parameters used in fire forecasts across the boreal forest, only the derived number of consecutive dry days stood out when investigating the total number of fires. After 10 dry days occur for any given grid box in either domain, the chance for a fire ignition greatly increases and can reach more than 50\% after 20 dry days. Similarly, the probability of fire ignition is low with less than 10 dry lightning strikes per grid box but approaches values of $30-50 \%$ as the number of dry strikes per grid box increases. Therefore, in any region of the boreal forest, after a long duration of dry weather, relatively sparse dry lightning activity can easily result in fire ignition, but if the number of dry days is low, a greater number of dry strikes per grid box is required to produce a similar chance for fire ignition. Furthermore, consecutive dry days may be a better measure of fire season variability than $500 \mathrm{hPa}$ heights in the eastern boreal forest because the total number of dry days is not necessarily affected by changes in the synoptic pattern (e.g. dry frontal passages).

If the data integration algorithm used in this study can be implemented in near real-time, dry lightning activity can be accounted for in fire weather forecasts, and the probability 
of a fire developing in subsequent days can be better estimated. One caveat pertaining to the data integration is the lack of fire information in cloudy conditions from MODIS. However, the uncertainties associated with this issue are likely taken into account through the holdover effect and the hits-and-misses analysis (Sect. 5.2) because: (a) the likelihood of having total cloud cover over a NARR grid box $\left(32 \times 32 \mathrm{~km}^{2}\right)$ is small, which favors the hits-and-misses analysis; and (b) the likelihood of a large cloud deck to persist over a NARR grid box during the holdover time window (2-3 days) is rare, especially in the summer months. It is expected that within the next decade, spatiotemporally collocated half-hourly fire, lightning, and cloud cover data obtained from future geostationary satellite observations (such as GOES-R, http://www.goes-r.gov/) could provide valuable constraints in analyzing the timing and localized mechanisms for lightning-induced fires. With climate change becoming a major issue, it is easy to see that increased low-level instability brought on by warmer temperatures can result in an enhanced potential for lightning activity and a greater chance for fire ignition. Future work will investigate the charge and peak current of each wet or dry lightning strike as it pertains to fire ignition. Furthermore, this study briefly described the influence of pre-season precipitation and other variables on fire intensity. Building on that analysis, nearfuture work will also incorporate ground-based observations of fires for analyzing the variables responsible for changes in the post-ignition fire intensity parameters (such as MODIS FRP) across the boreal forest.

Acknowledgements. We are all grateful to Environment Canada and The Bureau of Land Management (Alaska) for providing the lightning data used in this study. Early support for this project was provided by NASA through grants awarded under the ROSES Atmospheric Composition Modeling and Analysis Program (ACMAP to C. Ichoku), the Graduate Student Summer Program (to D. Peterson), and the Earth Science New Investigator Program (to J. Wang). The project is currently funded by a NASA Earth and Space Science Fellowship (to D. Peterson) and a NASA IDS grant. The Holland Computing Center at the University of Nebraska Lincoln is acknowledged for computational support. We also thank Mark Anderson and John Lenters for their constructive comments on the early version of the manuscript.

Edited by: T. Butler

\section{References}

Amiro, B. D., Logan, K. A., Wotton, B. M., Flannigan, M. D., Todd, J. B., Stocks, B. J., and Martell, D. L.: Fire weather index system components for large fires in the Canadian boreal forest, Int. J. Wildland Fire, 13, 391-400, 2004.

Anderson, K.: A model to predict lightning-caused fire occurrences, Int. J. Wildland Fire, 11, 163-172, 2002.

Boles, S. H. and Verbyla, D. L.: Comparison of three AVHRRbased fire detection algorithms for interior Alaska, Remote Sens. Environ., 72, 1-16, 2000.
Burgan, R. E., Klaver, R. W., and Klaver, J. M.: Fuel models and fire potential from satellite and surface observations, Int. J. Wildland Fire, 8, 159-170, 1998.

Burrows, W. R., King, P., Lewis, P. J., Kochtubajda, B., Snyder, B., and Turcotte, V.: Lightning occurrence patterns over Canada and adjacent United States from Lightning Detection Network observations, Atmos.-Ocean, 40, 59-80, 2002.

Choi, W., Kim, S. J., Rasmussen, P. F., and Moore, A. R.: Use of the North American Regional Reanalysis for Hydrological Modeling in Manitoba, Can. Water Resour. J., 34, 17-36, 2009.

Cummins, K. L., Krider, E. P., and Malone, M. D.: The US National Lightning Detection Network (TM) and applications of cloud-toground lightning data by electric power utilities, IEEE T. Electromagn. C., 40, 465-480, 1998.

Dissing, D. and Verbyla, D. L.: Spatial patterns of lightning strikes in interior Alaska and their relations to elevation and vegetation, Can. J. Forest Res., 33, 770-782, 2003.

Ebisuzaki, W.: National Climatic Data Center Data Documentation for NOAA Operational Model Archive and Distribution System (NOMADS) North American Regional Reanalysis, National Climatic Data Center, Ashville, NC, 11 pp., 2004.

Fauria, M. M. and Johnson, E. A.: Large-scale climatic patterns control large lightning fire occurrence in Canada and Alaska forest regions, J. Geophys. Res., 111, G04008, doi:10.1029/2006jg000181, 2006.

Flannigan, M. D. and Harrington, J. B.: A Study of the Relation of Meteorological Variables to Monthly Provincial Area Burned by Wildfire in Canada, J. Appl. Meteorol., 27, 441-452, 1988.

Flannigan, M. D. and Wotton, B. M.: Lightning-Ignited Forest Fires in Northwestern Ontario, Can. J. Forest Res., 21, 277-287, 1991.

Gao, B. C., Xiong, X. X., Li, R. R., and Wang, D. Y.: Evaluation of the Moderate Resolution Imaging Spectrometer special 3.95mu $\mathrm{m}$ fire channel and implications on fire channel selections for future satellite instruments, J. Appl. Remote Sens., 1, 013516, doi:10.1117/1.2757715, 2007.

Giglio, L., Descloitres, J., Justice, C. O., and Kaufman, Y. J.: An enhanced contextual fire detection algorithm for MODIS, Remote Sens. Environ., 87, 273-282, doi:10.1016/s00344257(03)00184-6, 2003.

Haines, D. A.: A lower atmosphere severity index for wildland fire, National Weather Digest, 13, 23-27, 1988.

Hall, B. L.: Precipitation associated with lightning-ignited wildfires in Arizona and New Mexico, Int. J. Wildland Fire, 16, 242-254, 2007.

Ichoku, C., Giglio, L., Wooster, M. J., and Remer, L. A.: Global characterization of biomass-burning patterns using satellite measurements of fire radiative energy, Remote Sens. Environ., 112, 2950-2962, 2008a.

Ichoku, C., Martins, J. V., Kaufman, Y. J., Wooster, M. J., Freeborn, P. H., Hao, W. M., Baker, S., Ryan, C. A., and Nordgren, B. L.: Laboratory investigation of fire radiative energy and smoke aerosol emissions, J. Geophys. Res.-Atmos., 113, D14S09, doi:10.1029/2007jd009659, 2008b.

Ichoku, C. and Kaufman, Y. J.: A method to derive smoke emission rates from MODIS fire radiative energy measurements, Ieee $\mathrm{T}$. Geosci. Remote, 43, 2636-2649, 2005.

Jordan, N. S., Ichoku, C., and Hoff, R. M.: Estimating smoke emissions over the US Southern Great Plains using MODIS fire radiative power and aerosol observations, Atmos. Environ., 42, 2007- 
2022, 2008.

Justice, C. O., Giglio, L., Korontzi, S., Owens, J., Morisette, J. T., Roy, D., Descloitres, J., Alleaume, S., Petitcolin, F., and Kaufman, Y.: The MODIS fire products, Remote Sens. Environ., 83, 244-262, 2002.

Kaufman, Y. J., Ichoku, C., Giglio, L., Korontzi, S., Chu, D. A., Hao, W. M., Li, R. R., and Justice, C. O.: Fire and smoke observed from the Earth Observing System MODIS instrument products, validation, and operational use, Int. J. Remote Sens., 24, 1765-1781, 2003.

Kaufman, Y. J., Justice, C. O., Flynn, L. P., Kendall, J. D., Prins, E. M., Giglio, L., Ward, D. E., Menzel, W. P., and Setzer, A. W.: Potential global fire monitoring from EOS-MODIS, J. Geophys. Res.-Atmos., 103, 32215-32238, 1998a.

Kaufman, Y. J., Kleidman, R. G., and King, M. D.: SCAR-B fires in the tropics: Properties and remote sensing from EOS-MODIS, J. Geophys. Res.-Atmos., 103, 31955-31968, 1998 b.

Kelha, V., Rauste, Y., Hame, T., Sephton, T., Buongiorno, A., Frauenberger, O., Soini, K., Venalainen, A., San Miguel-Ayanz, J., and Vainio, T.: Combining AVHRR and ATSR satellite sensor data for operational boreal forest fire detection, Int. J. Remote Sens., 24, 1691-1708, 2003.

Kim, S. J., Lee, M., Choi, W., and Rasmussen, P. F.: Utilizing North American Regional Reanalysis for climate change impact assessment on water resources in central Canada, Proceedings for the 13th World Water Congress, Montpellier, France, 14, 1-4, 2008.

Mesinger, F., DiMego, G., Kalnay, E., Mitchell, K., Shafran, P. C., Ebisuzaki, W., Jovic, D., Woollen, J., Rogers, E., Berbery, E. H., Ek, M. B., Fan, Y., Grumbine, R., Higgins, W., Li, H., Lin, Y., Manikin, G., Parrish, D., and Shi, W.: North American Regional Reanalysis, B. Am. Meteorol. Soc., 87, 343-360, 2006.

Potter, B. E., Winkler, J. A., Wilhelm, D. F., and Shadbolt, R. P.: Computing the low-elevation variant of the Haines index for fire weather forecasts, Weather Forecast., 23, 159-167, 2008.

Reap, R. M.: Climatological characteristics and objective prediction of thunderstorms over Alaska, Weather Forecast., 6, 309-319, 1991.

Roberts, G., Wooster, M. J., and Lagoudakis, E.: Annual and diurnal african biomass burning temporal dynamics, Biogeosciences, 6, 849-866, doi:10.5194/bg-6-849-2009, 2009.

Roberts, G., Wooster, M. J., Perry, G. L. W., Drake, N., Rebelo, L. M., and Dipotso, F.: Retrieval of biomass combustion rates and totals from fire radiative power observations: Application to southern Africa using geostationary SEVIRI imagery, J. Geophys. Res.-Atmos., 110, D21111, doi:10.1029/2005jd006018, 2005 .
Rorig, M. L. and Ferguson, S. A.: Characteristics of Lightning and Wildland Fire Ignition in the Pacific Northwest, J. Appl. Meteorol., 38, 1565-1575, 1999.

Rorig, M. L. and Ferguson, S. A.: The 2000 fire season: Lightningcaused fires, J. Appl. Meteorol., 41, 786-791, 2002.

Skinner, W. R., Flannigan, M. D., Stocks, B. J., Martell, D. L., Wotton, B. M., Todd, J. B., Mason, J. A., Logan, K. A., and Bosch, E. M.: A $500 \mathrm{hPa}$ synoptic wildland fire climatology for large Canadian forest fires, 1959-1996, Theor. Appl. Climatol., 71, 157-169, 2002.

Skinner, W. R., Stocks, B. J., Martell, D. L., Bonsal, B., and Shabbar, A.: The association between circulation anomalies in the mid-troposphere and area burned by wildland fire in Canada, Theor. Appl. Climatol., 63, 89-105, 1999.

Solaiman, T. and Simonovic, S. P.: NCEP-NCAR Reanalyses Hydroclimatic Data for Rainfall-Runoff Modeling on a Watershed Scale, CD Rom Proceedings, 33rd IAHR Congress: Water Engineering for a Sustainable Environment, 1100-1107, 978-94 90365-01-1, 2009.

Spracklen, D. V., Logan, J. A., Mickley, L. J., Park, R. J., Yevich, R., Westerling, A. L., and Jaffe, D. A.: Wildfires drive interannual variability of organic carbon aerosol in the western US in summer, Geophys. Res. Lett., 34, L16816, doi:10.1029/2007g1030037, 2007.

Stocks, B. J., Mason, J. A., Todd, J. B., Bosch, E. M., Wotton, B. M., Amiro, B. D., Flannigan, M. D., Hirsch, K. G., Logan, K. A., Martell, D. L., and Skinner, W. R.: Large forest fires in Canada, 1959-1997, J. Geophys. Res., 108, 8149, doi:10.1029/2001jd000484, 2002.

Werth, P. and Ochoa, R.: The evaluation of Idaho wildfire growth using the Haines Index, Weather Forecast., 8, 223-234, 1993.

Wooster, M. J.: Small-scale experimental testing of fire radiative energy for quantifying mass combusted in natural vegetation fires, Geophys. Res. Lett., 29, 2027, doi:10.1029/2002g1015487, 2002.

Wooster, M. J., Roberts, G., Perry, G. L. W., and Kaufman, Y. J.: Retrieval of biomass combustion rates and totals from fire radiative power observations: FRP derivation and calibration relationships between biomass consumption and fire radiative energy release, J. Geophys. Res.-Atmos., 110, D24311, doi:10.1029/2005jd006318, 2005.

Wooster, M. J., Zhukov, B., and Oertel, D.: Fire radiative energy for quantitative study of biomass burning: derivation from the BIRD experimental satellite and comparison to MODIS fire products, Remote Sens. Environ., 86, 83-107, 2003.

Wotton, B. M. and Martell, D. L.: A lightning fire occurrence model for Ontario, Can. J. Forest Res., 35, 1389-1401, 2005. 